\title{
BMJ Open Prostate cancer incidence and mortality in the Baltic states, Belarus, the Russian Federation and Ukraine
}

\author{
Ausvydas Patasius (D , ${ }^{1,2}$ Kaire Innos, ${ }^{3}$ Anton Barchuk, ${ }^{4,5}$ Anton Ryzhov, ${ }^{6,7}$ \\ Marcis Leja (D) , ${ }^{8,9}$ Janis Misins, ${ }^{9,10}$ Alesya Yaumenenka, ${ }^{11}$ Giedre Smailyte (D) ${ }^{1}$
}

To cite: Patasius A, Innos K, Barchuk A, et al. Prostate cancer incidence and mortality in the Baltic states, Belarus, the Russian Federation and Ukraine. BMJ Open 2019;9:e031856. doi:10.1136/ bmjopen-2019-031856

- Prepublication history and additional material for this paper are available online. To view these files, please visit the journal online (http://dx.doi. org/10.1136/bmjopen-2019031856).

Received 22 May 2019

Revised 05 September 2019

Accepted 06 September 2019

Check for updates

(c) Author(s) (or their employer(s)) 2019. Re-use permitted under CC BY-NC. No commercial re-use. See rights and permissions. Published by BMJ.

For numbered affiliations see end of article.

Correspondence to Dr Ausvydas Patasius; ausvydas.patasius@nvi.It

\section{ABSTRACT}

Background Prostate cancer incidence varies internationally largely attributable to differences in prostate-specific antigen (PSA) use. The aim of this study was to provide the most recent detailed international epidemiological comparison of prostate cancer incidence and mortality in six north-eastern European countries (Belarus, Estonia, Latvia, Lithuania, the Russian Federation and Ukraine).

Methods The number of incident prostate cancer cases was obtained from the countries national cancer registries. Prostate cancer mortality and corresponding population data were extracted from the WHO Mortality Database. Age-specific and age-standardised incidence and mortality rates were calculated (European Standard). The joinpoint regression model was used to provide an average annual percentage change and to detect points in time where significant changes in trends occurred. The observation period was between 13 (Ukraine) and 48 (Estonia) years regarding incidence and around 30 years regarding mortality.

Results The comparison of prostate cancer incidence in six European countries showed almost sixfold differences in the age-adjusted rates in most recent years with highest incidence rates in Lithuania and Estonia. Through the observation period, overall a continuous rise was seen in incidence in all countries and a continuous rise in mortality, with a stabilisation in Estonia and a decrease in Lithuania in recent years. Data limitations included a descriptive design using ecological data.

Conclusions A widespread use of PSA testing seems to be responsible for the changes in the epidemiology of the disease in north-eastern European countries. Substantial variation in the incidence of prostate cancer in the Baltic states suggests the possibility that PSA performance and utilisation spread have had a major influence on observed incidence trends, with a lack of effect on prostate cancer mortality.

\section{INTRODUCTION}

Prostate cancer was estimated to be the third most common cancer site in Europe in 2018 with 450000 cases being diagnosed and it being ranked as the fifth leading cause of cancer death with 107000 deaths. ${ }^{1}$ Although the aetiology of prostate cancer remains unknown, there are established risk factors

\section{Strengths and limitations of this study}

- This is a descriptive international study using national ecological data

- This study provides a detailed updated international epidemiological comparison of age-specific prostate cancer incidence and mortality trends in six north-eastern European countries.

- Lack of information on prostate-specific antigen (PSA) testing by age and calendar year for the study countries limits the opportunity for targeted analysis of association for PSA use with incidence data.

- Differences in data quality between countries and over time may have influenced the results.

- An additional study limitation was the lack of data on tumour stage.

for developing prostate cancer, including older age, a black racial background and a family history of the disease. ${ }^{2}$ Prevalence of other known risk factors, such as saturated fat intake, sedentary lifestyle and obesity, varies geographically worldwide and plays a role in prostate cancer incidence. ${ }^{2}$ Trends in prostate cancer incidence have been strongly influenced by prostate-specific antigen (PSA) testing $^{3}$ and widespread use of the PSA test is held responsible for the large rise in prostate cancer incidence in most European countries and worldwide. ${ }^{45}$ Incidence and mortality trends of prostate cancer have been analysed in several large-scale studies across Europe and worldwide. ${ }^{6-9}$ Incidence increase was mostly accompanied by a mortality decrease in western and northern European countries, while in the Baltic states, Belarus, the Russian Federation and Ukraine a steady mortality increase was found. ${ }^{710}$

The aim of this study was to provide the most recent detailed international epidemiological comparison of prostate cancer incidence and mortality in six north-eastern European countries (Belarus, Estonia, Latvia, Lithuania, the Russian Federation and Ukraine). 
Table 1 Study group characteristics and period range of incidence and mortality data obtained, and availability of incidence data in Cancer Incidence in Five Continents (CI5)

\begin{tabular}{|c|c|c|c|c|c|c|c|c|}
\hline \multirow[b]{2}{*}{ Country } & \multicolumn{3}{|l|}{ 2011-2015 } & \multicolumn{2}{|c|}{ Available for analysis } & \multirow[b]{2}{*}{$\begin{array}{l}\text { Included in } \\
\text { CI5 }\end{array}$} & \multirow[b]{2}{*}{$\begin{array}{l}\text { DCO } \\
(\%)\end{array}$} & \multirow[b]{2}{*}{$\begin{array}{l}\text { MV } \\
(\%)\end{array}$} \\
\hline & $\begin{array}{l}\text { Annual male } \\
\text { population } \\
\text { (millions) }\end{array}$ & $\begin{array}{l}\text { Average } \\
\text { annual } \\
\text { number of } \\
\text { incident } \\
\text { cases }\end{array}$ & $\begin{array}{l}\text { Average } \\
\text { annual } \\
\text { number of } \\
\text { deaths }\end{array}$ & Incidence & Mortality & & & \\
\hline Belarus & 4.4 & 3621 & 803 & 1990-2016 & $\begin{array}{l}1985-2003 \text { and 2008- } \\
2015\end{array}$ & 1988-2012 & - & 98.3 \\
\hline Latvia & 0.9 & 1118 & 387 & 1980-2016 & 1985-2015 & 1983-2012 & 6.0 & 85.3 \\
\hline Lithuania & 1.4 & 3180 & 537 & 1978-2016 & 1985-2016 & 1988-2012 & 1.7 & 94.5 \\
\hline $\begin{array}{l}\text { Russian } \\
\text { Federation }\end{array}$ & 66.6 & 33039 & 11172 & 1993-2015* & 1985-2015 & 1993-2012 & 0.1 & 79.0 \\
\hline
\end{tabular}

*Only from Saint Petersburg, 1998-2012-four cancer registries.

†For later period, not available due to lack of information from occupied regions of Ukraine.

DCO, death certificate only cases; MV, microscopically verified.

\section{METHODS}

The number of incident prostate cancer cases (International Classification of Diseases (ICD)-9 185 and ICD-10 C61) by 5-year age groups was obtained from the countries' national cancer registries from the start of data collection to the latest available. The period range of the obtained data is presented in table 1 . The breadth of incidence data received from the cancer registries was larger than that included in volumes of 'Cancer Incidence in Five Continents' (CI5), ${ }^{11}$ which are submitted to systematic quality control (table 1). Belarus, Estonia, Latvia and Lithuania have a long history of cancer registration, and data from those registries have been published in CI5 for decades. Cancer incidence data from Ukraine at the national level were published in volumes X-XI of the CI5 covering the period of 2003-2012. Four cancer registries from the Russian Federation were included in the latest volume of CI5, whereas previous data were published only from St. Petersburg. For the current analysis, national data aggregated from all regional registries were used. Data from these sources were previously used to evaluate the national cervical and breast cancer burden. ${ }^{12}$

Prostate cancer mortality data were extracted from the WHO Mortality Database by 5 -year age groups from 1985 to the latest year available. ${ }^{13}$ Data suitable for the analysis of time trends until 2015 or 2016 were available for four countries (Estonia, Latvia, Lithuania and the Russian Federation), but for Belarus, an analysis of time trends was carried out only until 2003 due to data gap in the period 2004-2007. For Ukraine, the mortality data were available from the years 1998-2012, and then for the years 2014 and 2015 . The observation period was between 13 (Ukraine) and 48 (Estonia) years for incidence and around 30 years for mortality. Corresponding population data by age and calendar year were also extracted from the WHO Mortality Database.

Age-specific and age-standardised incidence and mortality rates were calculated. Age-standardised incidence and mortality rates per 100000 person-years were standardised to the European population (Standard of 1976). Age-standardised rates were calculated for each calendar year for all ages combined, and age-specific rates for ages 50-74 and 75+ years. For comparison of mean incidence and mortality rates, years between 1995 and 1999 were defined as the pre-PSA period, and years between 2011 and 2015 as the post-PSA period. The pre-PSA period was defined according to the information on PSA availability in countries under study. The period 2011-2015 was defined as post-PSA under the assumption of widespread use of PSA tests.

Joinpoint regression was used to provide annual percentage changes (APC) and to detect points in time where statistically significant changes in the trends occurred. The average APC (AAPC) is a geometrically weighted average of APC values, with weights based on lengths of each segment during the whole observation period. In the absence of joinpoints, the APC's and AAPC's are equal. The joinpoint regression analysis identifies the best-fitting points ('joinpoints') where a significant change in the linear slope (on a log scale) of the trend is detected. The tests of significance use a Monte Carlo permutation method. Annual per cent changes were considered statistically significant if $\mathrm{p}<0.05$. Joinpoint analysis was performed for all ages combined and for the age groups 50-74 and 75+ years. A maximum number of three joinpoints were allowed for estimations. The minimum number of observations from a joinpoint to either end of the data was defined as three, and the 
minimum number of observations between two joinpoints as two (excluding any joinpoint that falls on an observation). Joinpoint software V.4.3.1.0 was used.

\section{Patient and public involvement}

There was no direct patient involvement. Only aggregated data were used.

\section{RESULTS}

\section{Incidence}

The comparison of prostate cancer incidence in six European countries showed almost a sixfold differences in the age-adjusted rates in the most recent years (table 2). Based on age-standardised rates in 2011-2015, the countries could be separated into two groups: high-incidence and low-incidence countries (ie, rates per 100000 above and below 100 cases, respectively). High incidence was observed in the Baltic states and low incidence in Belarus, the Russian Federation and Ukraine. An incidence increase was seen in all countries over the entire study period, with the annual APC ranging between 3.4 in Ukraine and 7.4 in Lithuania. Joinpoint analysis showed a continuous increase in incidence in Ukraine (no joinpoints) and generally increasing trends in Belarus, Latvia and the Russian Federation but with joinpoints suggesting different magnitudes of increase in different periods (see table 2 for joinpoints). Following a continuous rise in incidence and a marked increase, Lithuania and Estonia experienced decreases in incidence.

Prostate cancer incidence showed a general increase in countries in all age groups (figure 1). Among men aged 50-74 years incidence peaks were observed in Estonia and Lithuania, followed by an incidence decrease in Estonia since 2011 and in Lithuania since 2007. Results of detailed joinpoint analysis by age group are presented in online supplementary table 1 .

Age-specific incidence distributions in the period 19951999 before implementation of PSA in clinical practice indicated the highest incidence in all the countries in the 80-84 years age group, with the highest age-standardised rate of 753.0 cases per 100000 applying to Estonia (figure 2). During the period 2011-2015, the peak incidence shifted to younger age groups (70-74 and 75-79 years), with the highest age-specific rate of 1261.0 cases per 100000 in Lithuania applying to the $70-74$ years age group.

\section{Mortality}

The differences in mortality rates among all countries were relatively small (table 2). As for incidence rates, higher mortality rates were observed in the Baltic states, while lower rates were observed in Belarus, the Russian Federation and Ukraine (ASR above and below 30 cases per 100 000, respectively). All countries experienced a general mortality increase throughout the observation period, but in the most recent years, mortality stabilisation is observed in Latvia and Estonia, and a mortality decrease in Lithuania. Mortality trends in age-specific groups paralleled changes in overall mortality (online supplementary table 1 ).

Age-specific mortality distributions were similar in both periods, with the highest mortality rates in the age group $85+$ years (figure 2). No mortality shift between age groups was observed. Mortality rates differed markedly between two country groups: in the Baltic states, mortality rates were almost three times higher in the period 1995-1999. In the period 2011-2015, observed mortality rates in the oldest age groups doubled; however, the relative difference between the Baltic states and the other countries remained the same.

\section{DISCUSSION}

When comparing trends in prostate cancer incidence and mortality across six north-eastern European countries, differences were observed between two groups of countries. In the Baltic states, prostate cancer incidence was higher than in Belarus, the Russian Federation and Ukraine. Throughout the study period, a general rise was seen in incidence in all countries and a general rise in mortality, with a stabilisation in Estonia and decrease in Lithuania in recent years.

Differences in risk factors for specific cancers between regions, in international cancer control plans and in cancer screening strategies may have contributed to incidence and mortality differences between regions. ${ }^{14}$ The rising incidence may reflect the increased risk of disease or higher uptake of PSA tests. ${ }^{7}$ The incidence trends and patterns may be largely a function of the use of PSA testing. ${ }^{6}{ }^{8}$ Healthcare expenditure availability of medical resources may also be an important contributor to the patterns of international variation in prostate cancer incidence. ${ }^{15}$ Differences in data quality between countries and over time may have influenced the results.

Countries included in our study had different profiles of PSA testing uptake. In Lithuania, PSA became available in 2000, and in 2006, a nationwide PSA-based prostate cancer early detection programme was started. Since the start of the programme in the period of 2006-2010, around $72 \%-78 \%$ of the total eligible male population received at least one PSA test. No official prostate cancer screening programme has been introduced in Estonia, although in clinical practice, primary care physicians routinely offer the test to middle-aged and elderly men, and patients themselves actively request the test. ${ }^{16}$ According to a population-based health behaviour survey in 2016, the proportion of men who reported to have never had a PSA test was nearly $50 \%$ in the age group $55-64$ years, and nearly $60 \%$ in the age group $45-54$ years. ${ }^{17}$ In Latvia, PSA tests were not funded by the government and the frequency testing was determined by the urologist. ${ }^{18}$ In 2015, it was recommended that PSA testing be used from the age of 50 years onwards. Some prostate cancer screening activity was observed in other countries: Belarus from 2011 to 2012 had a pilot screening project in three regions of the capital city for men aged 50-65 


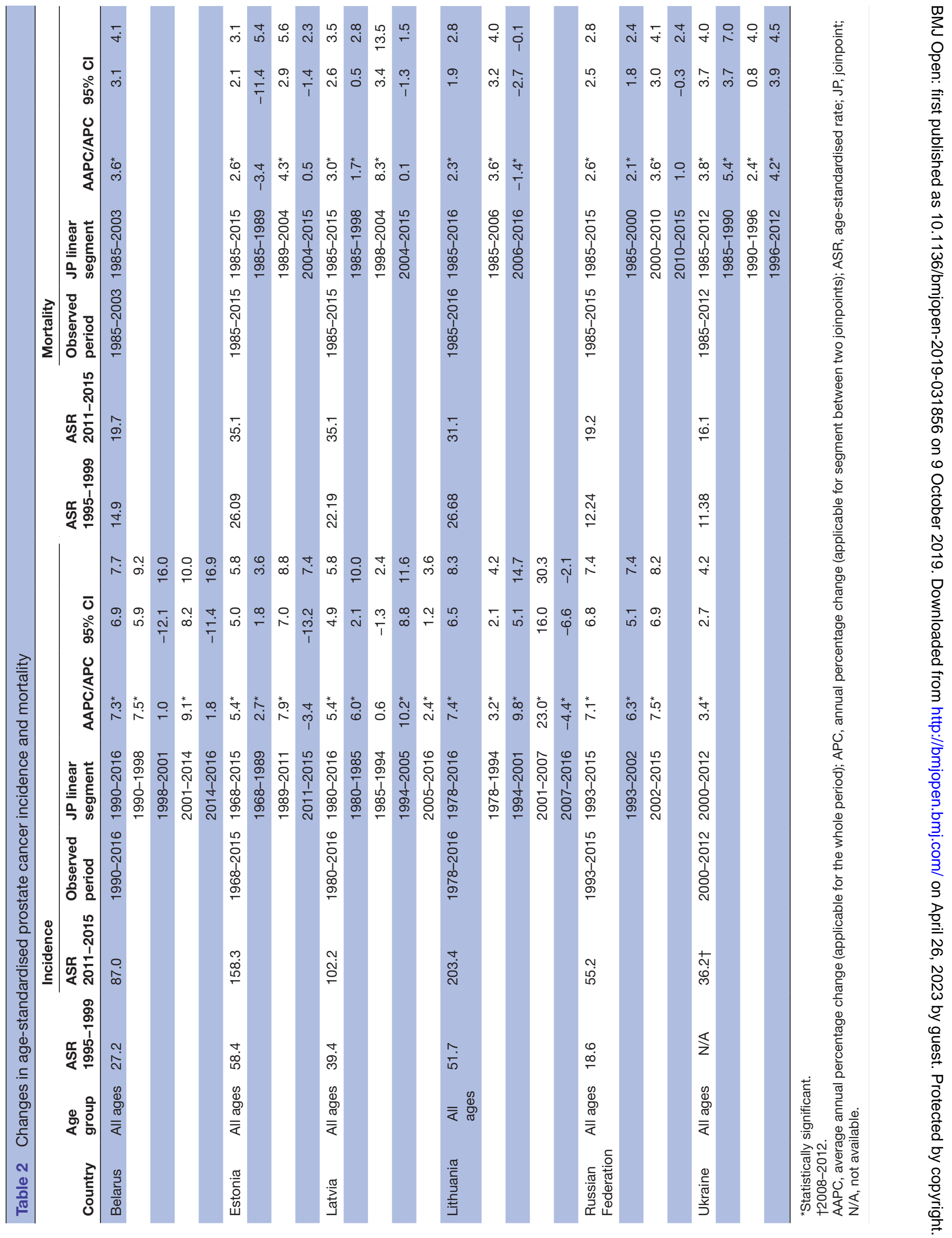




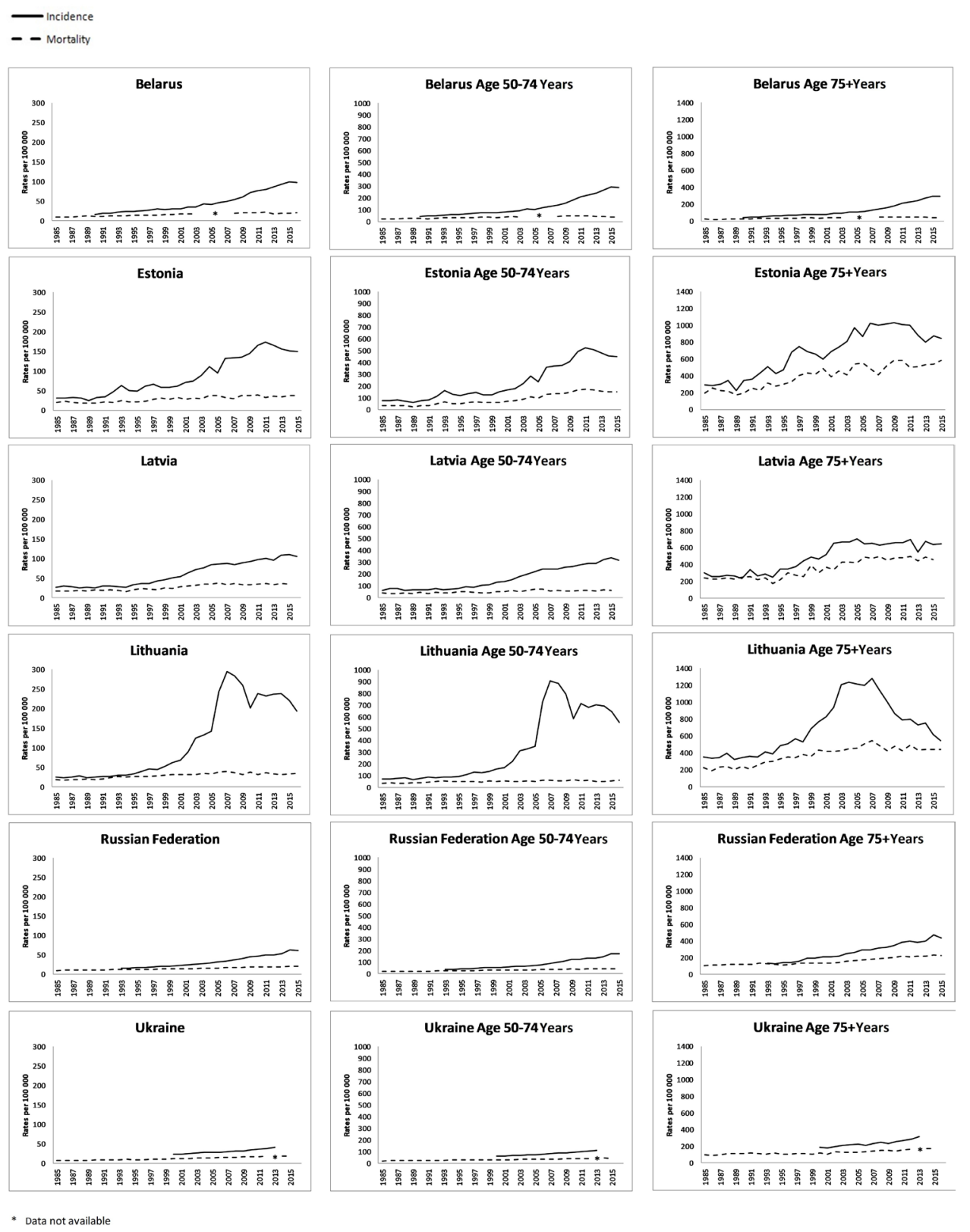

Figure 1 Trends in age-adjusted and age-specific prostate cancer incidence and mortality in six European countries.

years, with a PSA cut-off of $4 \mathrm{ng} / \mathrm{mL} \cdot{ }^{19}$ In the Russian Federation, PSA testing was introduced in the 1990s. Furthermore, PSA has been included in the national health check-up programme since 2013. This programme included other tests for other cancers and no formal and detailed information about the PSA cut-off value or settings for check-ups in this programme are available. In Ukraine, PSA check-ups for the population started quite late, compared with other countries. Formally, the PSA test was added to national guidelines for diagnostics of different locations and the state oncology programme of Ukraine, although no information regarding implementation and results of screening is available.

During the past 20 years, due to more extensive endoscopic benign prostate hyperplasia surgery, developing imaging techniques and PSA testing, higher prostate cancer rates have been observed in developed countries. ${ }^{5}$ A rapid increase in prostate cancer incidence appears mostly to be associated with the widespread use of the PSA test since the middle of 1980s. ${ }^{35-7}$ PSA use in clinical practice in north-eastern European countries began in the mid-to-late 1990s which reportedly reached almost $70 \%$ of males in some populations. ${ }^{7161820}$ There were sporadic occurrences of prostate cancer screening in the study countries. ${ }^{19}$ In Lithuania, in 2006, a prostate cancer early detection programme was introduced as part of a nationwide opportunistic PSA test-based prostate cancer screening initiative. Incidence changes in Lithuania paralleled changes in prostate cancer incidence in the USA reported for the early 1990s. ${ }^{18}$ There was a rapid incidence peak after the start of the screening programme, followed by a decrease thereafter. It was caused by initial detection 

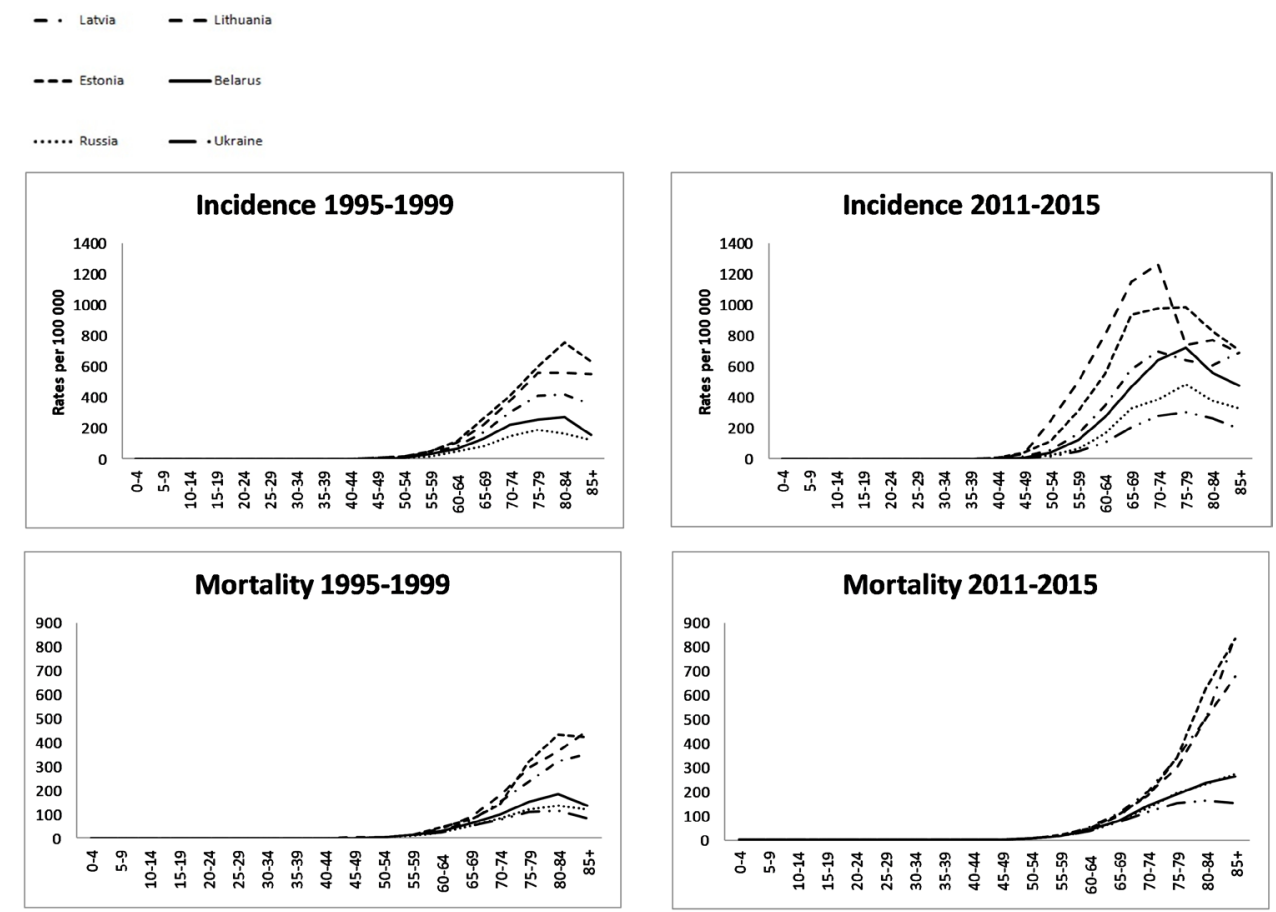

Figure 2 Age-specific incidence and mortality in periods 1995-1999 and 2011-2015.

of a so-called 'backlog' of prevalent cancers that had accumulated as a result of previous years' incidence, described by Mettlin. ${ }^{21}$ It is notable that similar incidence changes have been observed in Estonia, where the PSA uptake is relatively high in the male population, according to a health behaviour study reported in $2016 .{ }^{17}$ The role of PSA-testing in incidence trends is further supported by the fact that the incidence increase in Estonia was shown to be limited to localised cancers. ${ }^{16}$

Besides the tangible benefits of PSA testing, which appears to be small based on recent mortality data, the test may also cause unwanted harms, such as overdiagnosis or detection of indolent tumours, ${ }^{22}$ and as a consequence of overdiagnosis, overtreatment ${ }^{23}$ and reduction in life quality. ${ }^{24}$ Although PSA screening may be beneficial in an organised setting, ${ }^{25}$ the net effect of a higher PSA uptake at a population level could be negative due to side effects.

For the most part, prostate cancer is a latent, slowly progressing disease. A long period of time might be necessary before the mortality declines at the population level. Also, such a decline may occur in a different age group rather than the age at diagnosis. ${ }^{8}$ In our analysis, no mortality decrease was found in Lithuania in the age group 50-74 years and a slight mortality slope was observed in the age group 75+ years after 2006. This is consistent with the US data where a decrease in the mean age at diagnosis followed PSA use. ${ }^{23}$ The same effect is observed in our study. The highest age-specific incidence rates observed before implementation of PSA testing in clinical practice were seen in the 80-84 years age group in all countries. However, in more recent years, peak incidence rates shifted to younger age groups (ie, 60-64 and 70-74 years). By comparison, peak mortality rates shifted to older age groups from 80-84 to 85+ years after implementation of PSA testing in clinical practice. These changes could be a reflection of the PSA screening effect.

The Baltic states during the last decades have experienced a steep average incidence increase with a rather stable mortality, ${ }^{5}$ although mortality in our study in the Baltic countries has had a continuous growth, with stabilisation in Estonia and Latvia and a decrease in Lithuania since 2006 by $1.4 \%$ annually. The year when decrease started, coincidently, is the same as the start of the prostate cancer early detection programme in Lithuania. This could be misinterpreted as a success of the early effect of this programme. However, according to the data from randomised controlled PSA screening trials, the first mortality reduction is observed at least 9 years after the beginning of the trial. ${ }^{26}$ The mortality decrease in Lithuania, starting in the same year the screening started, is, therefore, unlikely to be due to the PSA-based screening. The high mortality rates observed after implementation of the PSA-based screening could be possibly due to the over-reporting of prostate cancer as an underlying cause of death in death certificates. Similarly, this was noted in the USA in 1991, when many men with undetected prevalent cancers were diagnosed with prostate cancer and were more likely to have prostate cancer assigned as a cause of death when dying. ${ }^{27}$ In a study in Norway, over-reporting of prostate cancer deaths was estimated to be $33 \%$, with significantly higher misattribution among older patients, who represent the large majority of prostate cancer deaths. ${ }^{28}$ Misattribution of the cause of death in Estonia was one explanation for increasing prostate cancer mortality. ${ }^{16}$ 


\section{CONCLUSIONS}

A widespread use of PSA testing seems to be responsible for the changes in the epidemiology of prostate cancer in north-eastern European countries. Substantial variation in the incidence of prostate cancer in the Baltic countries likely reflects the use of the PSA test in detecting prostate cancer. A lack of effect on prostate cancer mortality was observed. Guidelines for the use of the PSA-test as an early detection tool, including a joint and informed decision process of the physician and the patient, should be developed and adhered to in all the participating countries. This would help to minimise the harm associated with overdiagnosis, and to ensure that Belarus, the Russian Federation and Ukraine will not experience the marked incidence increases seen in the Baltic states.

\section{Author affiliations \\ ${ }^{1}$ Laboratory of Cancer Epidemiology, Nacionalinis vèžio institutas, Vilnius, Lithuania ${ }^{2}$ Faculty of Medicine, Institute of Health Sciences, Vilniaus Universitetas, Vilnius, Lithuania \\ ${ }^{3}$ Department of Epidemiology and Biostatistics, National Institute for Health Development, Tallinn, Estonia \\ ${ }^{4}$ Unit of Health Sciences, Faculty of Social Sciences, Tampere University, Tampere, Finland \\ ${ }^{5}$ Petrov Research Institute of Oncology, Saint Petersburg, The Russian Federation \\ ${ }^{6}$ Department of General Mathematics, Faculty of Mechanics and Mathematics, Taras Shevchenko National University of Kyiv, Kiiv, Ukraine \\ ${ }^{7}$ National Cancer Registry of Ukraine, National Cancer Institute of Ukraine, Kyiv, Ukraine \\ ${ }^{8}$ Institute of Clinical and Preventive Medicine, Riga, Latvia \\ ${ }^{9}$ Faculty of Medicine, University of Latvia, Riga, Latvia \\ ${ }^{10}$ Health Statistics Unit, Department of Research and Health Statistics, Centre for Disease Prevention and Control (CDPC) of Latvia, Riga, Latvia \\ ${ }^{11}$ N. N. Alexandrov National Cancer Centre of Belarus, Minsk, Belarus}

Contributors ML, AP and GS contributed to the study conception and design. $\mathrm{KI}$, $A B, A R, A Y, J M$ and GS contributed to the acquisition of data. AP and GS analysed and interpreted the data. AP drafted the manuscript. AB, KI, GS and AR critically revised the manuscript. AP and GS provided statistical analysis. GS supervised the manuscript. All the authors gave their final approval.

Funding The authors have not declared a specific grant for this research from any funding agency in the public, commercial or not-for-profit sectors.

Competing interests None declared.

Patient consent for publication Not required.

Ethics approval This article does not contain any studies with human participants or animals performed by any of the authors.

Provenance and peer review Not commissioned; externally peer reviewed.

Data availability statement All data relevant to the study are included in the article or uploaded as supplementary information.

Open access This is an open access article distributed in accordance with the Creative Commons Attribution Non Commercial (CC BY-NC 4.0) license, which permits others to distribute, remix, adapt, build upon this work non-commercially, and license their derivative works on different terms, provided the original work is properly cited, appropriate credit is given, any changes made indicated, and the use is non-commercial. See: http:// creativecommons.org/licenses/by-nc/4.0/.

ORCID iDs

Ausvydas Patasius http://orcid.org/0000-0003-3874-2723

Marcis Leja http://orcid.org/0000-0002-0319-8855

Giedre Smailyte http://orcid.org/0000-0001-8365-543X
REFERENCES

1. Ferlay J, Colombet M, Soerjomataram I, et al. Cancer incidence and mortality patterns in Europe: estimates for 40 countries and 25 major cancers in 2018. Eur J Cancer 2018;103:356-87.

2. Gann PH. Risk factors for prostate cancer. Rev Urol 2002;4 Suppl 5(Suppl 5):S3-S10.

3. Kvåle R, Auvinen A, Adami H-O, et al. Interpreting trends in prostate cancer incidence and mortality in the five Nordic countries. J Natl Cancer Inst 2007:99:1881-7.

4. Hayes JH, Barry MJ, Kantoff PW, et al. Prostate-Specific antigen screening for prostate cancer: a decision-analytical perspective. BJU Int 2007;100:486-8.

5. Center MM, Jemal A, Lortet-Tieulent J, et al. International variation in prostate cancer incidence and mortality rates. Eur Urol 2012;61:1079-92.

6. Zhou CK, Check DP, Lortet-Tieulent J, et al. Prostate cancer incidence in 43 populations worldwide: an analysis of time trends overall and by age group. Int $J$ Cancer 2016;138:1388-400.

7. Bray F, Lortet-Tieulent J, Ferlay J, et al. Prostate cancer incidence and mortality trends in 37 European countries: an overview. Eur $\mathrm{J}$ Cancer 2010;46:3040-52.

8. Neppl-Huber C, Zappa M, Coebergh JW, et al. Changes in incidence, survival and mortality of prostate cancer in Europe and the United States in the PSA era: additional diagnoses and avoided deaths. Ann Oncol 2012;23:1325-34.

9. Fitzmaurice C, Dicker D, Pain A, et al. The global burden of cancer 2013. JAMA Oncol 2015;1:505-27.

10. Bosetti $C$, Bertuccio $P$, Chatenoud $L$, et al. Trends in mortality from urologic cancers in Europe, 1970-2008. Eur Urol 2011;60:1-15.

11. International Agency for Research on Cancer. Cancer incidence in five continents. Available: http://ci5.iarc.fr [Accessed 15 Jan 2019].

12. Barchuk $A$, Bespalov $A$, Huhtala $H$, et al. Breast and cervical cancer incidence and mortality trends in Russia 1980-2013. Cancer Epidemiol 2018;55:73-80.

13. Who mortality database, 2018. Available: http://www.who.int/ healthinfo/mortality_data/en/ [Accessed 07 Jul 2018].

14. Welch HG, Brawley OW. Scrutiny-Dependent cancer and self-fulfilling risk factors. Ann Intern Med 2018;168:143-4.

15. Neupane S, Bray F, Auvinen A. National economic and development indicators and international variation in prostate cancer incidence and mortality: an ecological analysis. World J Urol 2017;35:851-8.

16. Innos K, Baburin A, Kotsar A, et al. Prostate cancer incidence, mortality and survival trends in Estonia, 1995-2014. Scand J Urol 2017:51:442-9.

17. Tekkel M, Veideman T. Health behavior among Estonian adult population. Tallinn Development NIfH; 2016.

18. Gondos A, Krilaviciute A, Smailyte G, et al. Cancer surveillance using registry data: results and recommendations for the Lithuanian national prostate cancer early detection programme. Eur $J$ Cancer 2015;51:1630-7.

19. Sukonko O, Krasny S, Tarend D. First results of prostate cancer screening programme in Belarus. EAU Baltic Meeting Vilnius: European Urology Supplements, 2014: 13. e1185.

20. Krilaviciute A, Smailyte G, Brenner $\mathrm{H}$, et al. Cancer survival in Lithuania after the restoration of independence: rapid improvements, but persisting major gaps. Acta Oncol 2014;53:1238-44.

21. Mettlin C. Impact of screening on prostate cancer rates and trends. Microsc Res Tech 2000;51:415-8.

22. Draisma G, Etzioni R, Tsodikov A, et al. Lead time and overdiagnosis in prostate-specific antigen screening: importance of methods and context. J Natl Cancer Inst 2009;101:374-83.

23. Welch HG, Albertsen PC. Prostate cancer diagnosis and treatment after the introduction of prostate-specific antigen screening: 19862005. J Natl Cancer Inst 2009;101:1325-9.

24. Wilt TJ, MacDonald R, Rutks I, et al. Systematic review: comparative effectiveness and harms of treatments for clinically localized prostate cancer. Ann Intern Med 2008;148:435-48.

25. Roobol MJ. Screening for prostate cancer: are organized screening programs necessary? Transl Androl Urol 2018;7:4-11.

26. Schröder FH, Hugosson J, Roobol MJ, et al. Screening and prostatecancer mortality in a randomized European study. N Engl J Med 2009;360:1320-8.

27. Feuer EJ, Merrill RM, Hankey BF. Cancer surveillance series: interpreting trends in prostate cancer--part II: Cause of death misclassification and the recent rise and fall in prostate cancer mortality. J Natl Cancer Inst 1999;91:1025-32.

28. Löffeler S, Halland A, Weedon-Fekjær $\mathrm{H}$, et al. High Norwegian prostate cancer mortality: evidence of over-reporting. Scand J Urol 2018;52:122-8. 